\title{
A ESCRITA SOCIOGRÁFICA COMO DIDÁTICA TRANSCRIADORA E PRODUTORA DE PRESENÇA
}

\author{
SOCIOGRAPHIC WRITING AS TRANSCREATING AND PRESENCE \\ PRODUCING DIDACTICS
}

\section{LA ESCRITA SOCIOGRÁFICA COMO DIDACTICA TRANSCREADORA Y PRODUCTORA DE PRESENCIA}

\author{
Máximo Daniel Lamela Adó ${ }^{1}$ \\ Sandra Mara Corazza ${ }^{2}$
}

\begin{abstract}
RESUMO: O texto apresenta alguns aspectos da literatura de Georges Perec com o intuito de discernir sobre uma escrita sociográfica que atue como uma didática transcriadora do cotidiano e produtora de presença presença produzida por um modo de operar a escritura com a finalidade de recriar atmosferas e estados de espírito constituídos por elementos pouco desenvolvidos do movimento de uma aula, isto é, da relação com suas materialidades em fluxo. Procura se orientar na escrita sociográfica de Perec para poder dar a ler o encontro dos corpos docentes e discentes com os da outras matérias de seus entornos e que afetam, também, seus intelectos. Trata-se de desenvolver procedimentos para uma didática transcriadora do cotidiano se apropriando da leitura e escrita literária como pensamento.
\end{abstract}

PALAVRAS-CHAVE: Sociografia. Didática. Transcriação. Escrileituras.

\begin{abstract}
This paper presents some aspects of Georges Perec's works in order to discern a sociographic writing that functions as a didactics that both transcreates daily life and produces presence - a presence produced by a way of operating in writing with the purpose of recreating atmospheres and states of mind consisting of class elements that have been scarcely developed, i.e. the relationship with their flowing materialities. It also seeks for guidance from Perec's sociographic writing to enable the reading of the meeting of teachers and students with other surrounding matters that also affect their intellects. It is about developing procedures for a transcreating didactics of daily life by appropriation of literary writing as thought.
\end{abstract}

KEYWORDS: Sociography. Didactics. Transcreation. Reading-writings.

RESUMEN: El texto se preocupa en presentar algunos aspectos de la literatura de Georges Perec con el intento de discernir una escrita sociográfica que actúe como una didáctica transcreadora de lo cotidiano y productora de presencia - presencia producida por un modo de operar la escritura con la finalidad de recrear atmósferas y estados de espíritu constituidos por elementos poco desarrollados del movimiento de un aula, es decir, la relación con sus materialidades en flujo. Busca orientarse en la escrita sociográfica de Perec para poder dar a leer el encuentro de los cuerpos docentes y discentes con los de otras materias de sus entornos y que afectan también sus intelectos. Se trata de desarrollar procedimientos para una didáctica transcreadora de lo cotidiano apropiándose de la lectura y escrita literaria como pensamiento.

\footnotetext{
${ }^{1}$ Doutor em Educação pela Universidade Federal do Rio Grande do Sul (UFRGS). Atua como pesquisador colaborador da UFRGS - Rio Grande do Sul, Porto Alegre - Brasil e Bolsista de Pós-Doutorado - PDJ do CNPq. E-mail: máximo.lamela@gmail.com.

2 Doutora em Educação pela Universidade Federal do Rio Grande do Sul (UFRGS). Professora do Departamento de Ensino e Currículo da Universidade Federal do Rio Grande do Sul (UFRGS), Porto Alegre, RS - Brasil. E-mail: sandracorazza@terra.com.br.

Recebido em: 30/05/2015 - Aprovado em: 03/07/2015.
} 
PALABRAS CLAVE: Sociografía. Didáctica. Transcreación. Escrilecturas.

\section{INTRODUCCIÓN}

El texto expone un intento para pensar una educación de la inmanencia valiéndose de procesos de creación literaria como procedimientos didácticos. Se utiliza de la literatura de Georges Perec como componente hipotextual para traducir, al modo de una transcreación, algo del cotidiano educacional a partir del aula. Entiende esos procesos, elaborados por la escritura, como una actividad de traducción transcreadora que se despliega como investigación de la vida cotidiana.

En ese sentido recurre a la literatura de Georges Perec entendiéndola como un procedimiento transcreador del espacio, de un discurso sobre las cosas y de una intensa relación con otros textos. Así el hacer de esa escritura se transfigura como pensamiento y, además de donatario de sentido, ofrece procedimientos poéticos para establecer conexiones transtextuales figuradas en textos y modos de proceder didácticamente. En ese sentido es que denominamos ese tipo de escritura literaria, como la de algunos textos de Georges Perec, de sociografía.

Es importante decir que la sociografía que caracterizamos aquí se dimensiona como actividad que difiere de una sociología en muchos sentidos pero principalmente por asomarse más para un gesto poético que para una actitud interpretativa de fenómenos sociales.

El resultado de escritura de esta sociografía se presenta como un instrumento para hacer un trazado de la imaginación pública hilvanado como una red discursiva de lo que circula sobre lo social y como posibilidad de definir un presente. Ese trazado se comporta como autobiográfico por admitir la singularidad de cada lector y de cada lectura, pero sin individualizarla y tampoco dejar de ver que su potencia se da por un atravesamiento de lo colectivo. Es decir, con Jean-Luc Nancy (2006), que esa potencia se comporta como un estar singular plural; una producción siempre relacional entre la singularidad de un sujeto y la colectividad de lo social. En ese sentido no se podría concebir la existencia de los entes, vivientes o no, en separado. Para esa concepción toda existencia es co-existente, lo singular es plural y lo plural singular. La literatura de Walt Whitman, como presentada por Gilles Deleuze, puede servir de perspectiva y expresión de esa dimensión, es decir, la que nos da a leer que no existe historia privada que no sea pública, política y popular. Para Deleuze, al mencionar la obra de Whitman, toda literatura deviene como un asunto del pueblo; la autobiografía más personal es necesariamente colectiva (1997, p.68).

En ese sentido la práctica de una escrita sociográfica tratada como didáctica transcreadora se torna prolífica como instrumento para una educación de la diferencia y de la inmanencia, o sea, para una educación que difiere de sí misma en la medida en que se repite como alteridad multiforme y se hace presente al no crear para sí un meta-relato que la proyecte para otro plan que el de su propia práctica del presente. 
La escrita sociográfica - en el sentido de colocar por escrito modos de operar una relación con lo cotidiano - , sirve como operadora de una didáctica de la traducción que acarrea una oportunidad de la producción de presencias por el devenir que sobreviene de su apertura. La presencia se produce, también, por cierto efecto de la escritura. Ella misma y su materialidad conllevan diferentes fuerzas intelectuales que están más allá del sentido formal que componen el conjunto de sus palabras. Se trata de una atmosfera, un estado de espíritu que podríamos llamar de tonalidad afectiva [Stimmung] que, como en el escuchar de una música, coloca al oyente en una condición compleja que afecta a todo su cuerpo y mente. Se trata de un estado que a pesar de que no comprendamos su dinámica o encontremos su causa no podemos dejar de dar atención a su existencia, como presencia, y anotar — por una escrita siempre de invención-, sus variantes.

Con Perec, podemos afirmar que si no interrogamos a lo habitual eso que ahí pasa no nos interroga y no lo planteamos como problema; lo vivimos sin pensar como si no fuese portador de información y cargado de fuerzas intelectuales e intelectivas que dan potencia a las acciones de nuestra vida. "Pero nuestra vida, ¿dónde está? ¿Dónde está nuestro cuerpo? ¿Dónde nuestro espacio?

Podríamos pensar que un aula, como en la lectura de una novela, produce un efecto y, talvez, ese efecto pueda ser colocado en presencia vía la materialidad de una escritura descriptiva de la materialidad que la compone. Como los inventarios hechos por Perec.

Por lo tanto admitimos que no es necesario que tras cada acontecimiento haya un escándalo “[...] como si la vida no debiera revelarse nada más que a través de lo espectacular, como si lo elocuente, lo significativo fuese siempre anormal: cataclismos naturales o calamidades históricas, conflictos sociales, escándalos políticos...,", o sea, "lo que ocurre cada día y vuelve cada día. Lo trivial, lo cotidiano, lo evidente, lo común, lo ordinario, lo infraordinario, el ruido de fondo, lo habitual, ¿cómo dar cuenta de ello, cómo interrogarlo, cómo describirlo?" (PEREC, 2010)

Cómo hablar de esas cosas comunes - que pueden ser leídas en la atmosfera de una novela, de una pintura, una película o, también, sentidas en el ambiente de un aula - cómo traducirlas o darles materialidad y presencia. Con esas interrogativas nos asomamos a pensar una escrita que llamamos de sociográfica y con ella hilvanar una práctica que sea didáctica pero no didactizante en el sentido de que no se reduzca a modelos de instrucción. Pero afirme modos de operar que potencialicen, con diferencia, sus prácticas a cada hacer que provoca la multiplicidad antes que lo homogéneo y universal.

\section{ASPECTO AUTOBIOGRÁFICO DE LA TEORIA}

Paul Valéry dice que no existe teoría que no sea un cuidadoso fragmento preparado de alguna autobiografía (VALÉRY, 1991, p.204), admitiendo, con eso, que toda teoría está formada por una existencia humana e intelecto que le da sentido y significado en su propio 
campo de posibilidades. Siguiendo con el pensamiento valéryano, afirmamos que todo lo que se puede definir luego se distingue del espíritu productor oponiéndose a él, o sea, el trabajo de una obra del intelecto solamente existe como acto y como proceso de producción. Lo resultante de ese proceso, sea un producto material o abstracto como suena ser una idea, se torna un objeto y su uso es completamente extraño a las condiciones de su producción, es decir, de su proceso de creación.

Volverse a ese acto de producción del intelecto, más que para sus productos, es como admitir cierto fracaso de los resultados y, en esa calidad, subrayar las fuerzas del proceso sin dejar de tener como afirmación del mismo la materialidad del producto. Con eso, insistir en lo que constituye una expresión inmanente o inmanencia expresiva como marca de una variación de si a través de un hacer, o sea, una inmanencia expresiva de todo lo que se hace (DELEUZE, 1996).

La producción literaria de Georges Perec comparte de esa relación autobiográfica que podemos leer en Paul Valéry desde su primer publicación Les choses en 1965. Pero lo que nos interesa señalar la idea - existente en varios de sus proyectos literarios - , de escudriñar los propios pensamientos y acciones con la intención de contornar una miopía a respecto de todo lo que nos constituye como vivientes de una urbanidad. Hablar de detalles que nos componen como seres pensantes y productores en el trato con lo cotidiano.

Se trata de un cuidado que tiene como procedimiento una búsqueda en lo usual como modo de prefigurar detalles, siempre inconsistentes, de cosas que hacemos y nos producen como vivientes relacionales. Lo que hay en la escritura de Georges Perec es un modo sociográfico de transponer lo infraordinário en literatura, es decir, leer la propia literatura y el arte como maneras de escribir sobre lo social.

Algunos procedimientos literarios de Perec experimentan una traducción intersemiótica de su experiencia como viviente, ya que parece preocuparse en describir y encontrar maneras de instaurar un efecto de lo social a través de la escritura, no solamente en el contenido, o en algo que se cuente, pero especialmente en la forma. Lo importante está más para cómo procesa lo que se puede escribir, de lo que en algo que quiera contar. A la vez, lo que se escribe se torna chirlo. Hay algo en el lenguaje que truca. Todavía que se utilice de un lenguaje descriptivo y aparentemente comunicativo y transparente hay siempre algo, un modo sintáctico, una falla, una incompletitud que lanza la lectura a un sentido ambivalente, o mejor dicho, lanza la escritura a una paradójica del sentido.

Para Georges Perec los elementos autobiográficos acceden una historia colectiva que él la afirma con el gesto de estar volcado a sí mismo y a su entorno. Con eso se estimula una escrita descriptiva y colmada en detalles del espacio observado. Por lo tanto, lejos de una universalización generalizadora de regularidades identitárias, por preocuparse con los detalles, es afirmadora de acontecimientos singulares en su condición de potencia y no de realización. O sea, no se trata de una descripción referencial, es decir, que tenga lo descripto 
como una verdad observada, pero, como una noción de inventividad impuesta por una rigurosa condición de atención a las relaciones entre el observador y lo observado. Para Perec esta sería una manera de hacer una antropología ya no de lo exótico, sino de lo endótico y de lo infraordinario. Hacer una antropología, dice Perec, que hable de uno mismo, que busque en nosotros lo que fuimos a buscar y saquear en los otros (PEREC, 2010, p. 23).

En su práctica de escritura Georges Perec expone la idea de que diferencia y repetición no son opuestos, pero que la repetición produce una visibilidad de la diferencia (NORDHOLT, 2008). A la manera del texto de Jorge Luis Borges Pierre Menard, autor del Quijote (1995b, p.43-54) lo que se repite, es decir, lo que vuelve, vuelve como una traducción creadora. Una traducción de algo que se establece como original, pero se transforma y pierde su estatus de original al hacerse presente en la medida que cambia, por influencia e interrelación, el pasado leído como una proyección presente y en proceso.

De ese modo, volviendo a Perec, se constituye una literatura como una manera de inventariar cosas del cotidiano, de repetirlo con diferencia, de instaurar una atención a algo como las sensaciones de lo inaprehensible. En Tentative d'épuisement d'un lieu parisien de 1974, opera con una anotación del presente y lleva esa práctica a un experimento de agotamiento. Bosqueja fichas con anotaciones de la observación del espacio, con fecha, hora, lugar, clima, tiempo, anudado a la descripción de cosas vistas como letras, frases, simbologías utilizadas en la comunicación urbana, clasificaciones de orden variado. De ese modo Perec actúa como una especie de botanista urbano, un urbanologista poético.

Así se puede leer, en la escritura de Perec, que toda percepción es limitada y, por eso, siempre inventiva al mismo tiempo que no pasa de una repetición descriptiva de lo que ya se conoce. Su proyecto de coleccionador de trazos tangibles de la vida urbana construye una textualidad que se vale del empleo descriptivo de las cosas como una manera de poblar espacios con un conjunto de restos de nuestros días. Todo se torna materia para un texto sociográfico que es, en la primera y última mirada, un texto poético habitado por nombres en suspensión - de muchas cosas. Nombres que en una instancia lectora se tornan duplos o, a lo mejor, múltiplos. Fallan en su condición referencial.

Escribir es traducir, nos dice Paul Valéry (1956), y cuando lo hacemos estamos creando un duplo de nosotros mismos, inventando otro espacio vital que pueda ser nuestro mientras somos, constantemente, invadidos por ideas ajenas que, paradójicamente, son nuestras y nos llegan por medio de un improviso compartido con una búsqueda (VILAMATAS, 2002). Son elementos de ese tipo que habitan un aula a la mediada que en ella se hace presente el compartir de una búsqueda, o sea, una tarea volcada para un hacer relacional y no de transmisiones y saberes establecidos. 


\section{SOCIOGRAFÍA Y EDUCACIÓN}

Admitimos, con Thomas Kuhn (1998), que para la ciencia, la teoría del conocimiento y la filosofía, ningún hecho es aisladamente apenas un hecho, pues que todo hecho conlleva teoría, o sea, presupone un campo que lo explica a través de conceptos previamente elaborados y aceptos consensualmente en la esfera de su uso. Esa aceptación hace con que se entienda el conocimiento como una actividad situacional. $\mathrm{O}$ sea, aquellos que la operan les donan sentido en reciprocidad con aquellos que la utilizan.

Si estamos de acuerdo con Paul Valéry (1991), de que toda teoría está cargada de elementos autobiográficos, accedemos a la idea de que todo hecho está, voluntaria o involuntariamente, adquiriendo significado a partir de una vida que lo subyace. Esta, a su vez, está dotada de movimientos que la conforman en sus acciones cotidianas, o sea, los movimientos que esa vida produce en la sociedad en que vive. En ese sentido nos interesa la idea de sociografía entendiendo que una escrita, a respecto de una vida en sociedad, se vale - explícita o implícitamente - de modos de la creación literaria y de las artes como potencia para poner en perspectiva y con eso producir la propia vida como una existencia inmanente.

En las ciencias humanas y sociales, la filosofía y el arte - especialmente cuando pensamos su desarrollo por intermedio de la investigación y enseñanza, o sea, Educación sería peligroso mantener el pensamiento separado de la experiencia del mundo que se está estudiando, pues entendemos que el pensamiento se coloca en funcionamiento cuando ocurre esta relación. Mejor dicho, solamente cuando algunas conexiones son posibilitadas por los encuentros. Para decirlo de otro modo, nos interesa señalar que un pensamiento ocurre cuando realidad y ficción se cruzan y sus fronteras quedan borradas, pues aquello que las define está colocado en régimen de sospecha.

Se logra concebir que el mundo pueda ser leído como ficción y, en esa medida, es la ficción un elemento constituyente de un pensamiento de la realidad. Es en ese sentido, en el de la relación entre ficción y realidad, que se produce algo nuevo. Algo que puede proliferar como desconocido al trazar de otro modo aquello que ya se conoce.

Cuando optamos por la noción de sociografía para subrayar un trazado de los hechos cotidianos, es por entender - en un ámbito práctico — que al hablar en una sociografía estamos imaginando que la observación de procesos sociales es concebida por una escrita que se decide, también, como una autocreación y como autobiografía. De ese modo, afirmamos que toda escrita está coadunada a una lectura y que estas, escrita y lectura - tratadas como movimientos que reconocemos como escrileituras [escrilecturas] (CORAZZA, 2008; 2013) -, son actividades constitutivas de la vida cotidiana, sus discursos y relatos, gestos e imágenes. Subrayando que una sociografía permuta una postura interpretativa de los fenómenos sociales por una escritura descriptivo-inventiva de tales fenómenos, y estos entran 
en relación como asociaciones interactivas: movimientos que se realizan en red y de modo autocreador.

El observador - como un sociografísta - se instala como un artista que se da cuenta que al moldar la materia es moldado por ella incluso cuando esa materia sea él mismo. Se trata de entender la relación de lo que estamos llamando de sociografía como un elemento constitutivo al mismo modo de lo que llamamos de educación, o sea, un elemento componente de prácticas de escritura que transfieren, a uno mismo y a las relaciones por ende establecidas, una performatividad de la invención y una producción de inventividad. Se trata de traducir y renovar aspectos de la vida a la manera de producir expresividades que emitan posibilidad de repercusión. Como dijo Bachelard (1989), la repercusión - diferente de la resonancia que sería un modo de dispersar los distintos planes de la vida en el mundo - nos permite leer un poema hablándolo como si fuera nuestro, mejor dicho, haciendo de lo leído materia singular que nos invita a un ahondamiento de nuestra propia existencia. En la repercusión somos tomados por una multiplicidad que las resonancias dispersan.

Tomada en ese sentido, una escrita sociográfica funciona como la repercusión, anotada, de una experiencia de lo social. Es decir, una materia autobiográfica y de un acercamiento a lo colectivo.

\section{REALIDAD E IDENTIDAD}

Una verdad, cuando instituida, está configurada por los mismos principios y conjeturas de realidad que le dan sentido. Podemos afirmar con Flusser (2006), que una realidad es una ficción corroborada por un campo consensual y hegemónico; luego, una realidad es constituida por un principio de identidad. Flusser se apoya en el dictamen wittgensteiniano que dice que los matemáticos nada descubren: inventan (WITTGENSTEIN, 1991); y, en ese contexto, sus invenciones son realidades verificables.

Nos interesa afirmar que así también funciona la educación y, evidentemente, la sociedad. Un currículo dimensionado por la teoría que, de algún modo, lo justifica se desarrolla como una cuestión de identidad. Como manifiesta Silva (2011, p. 16) las teorías del currículo están activamente comprometidas en la actividad de garantizar el consenso y obtener hegemonía. Estas teorías están ubicadas en un campo epistemológico social.

Las realidades instauradas por las invenciones que conlleva un currículo establecen lugar, espacio, territorio; conforman identidades y constituyen relaciones de poder. En ese sentido son, también, constituyentes de un texto y un discurso que puede ser leído como autobiográfico, pues organiza la identidad de quienes operan y son operados por él (IBIDEM, p. 150).

Todavía se puede observar que el objeto de investigación de una sociología es aquello que se denomina realidad social, pero lo que el sociólogo realiza no es extraer una muestra de 
la realidad, pues eso carece de posibilidad. Lo que es posible, vía análisis estadísticas, por ejemplo, es retirar una muestra de datos que subsidian una interpretación que se designa como realidad. Lo que el sociólogo o científico social hace es designarle un contexto (LEPETIT, 2001), encadenando una interrelación de circunstancias que acompañan un hecho, lo que implica el conjunto de discursos que le da valor, o sea, un texto. En esa perspectiva el estatuto de toda definición sociológica está situado entre una observación singular y un concepto universal - pensando ese universal por la noción de Karl Popper observada por Bernard Lepetit (LEPETIT, 2001), o sea, por la idea que un concepto puede ser considerado como universal cuando dispensa una referencia directa a un nombre propio - y por ser universal solo tiene validad cuando el parentesco de los contextos que definen su permanencia histórica le dan fuerza operatoria (IBIDEM, p.127). De esa noción proviene una circularidad que afirma que un concepto histórico solo adquiere sentido delante de ese recorte del mundo al cual él mismo da sentido. Se trata de una lógica contradictoria que, simultáneamente es operacional, una vez que se admita que la inteligibilidad del mundo no se separa del proceso de investigación. Dicho al modo de Lepetit, no se separa el modelo de la modelización.

Asimismo, la pertinencia de una observación singular — de una experiencia singular - interactúa como una valorización extraordinaria, o sea, más allá del consenso. Observase, sin embargo, que si una sociografía no persiste para un más allá de una observación singular, según Passeron (1989), esta no puede, no está apta, a movilizar una inteligibilidad construida para el consenso y, en ese sentido, no podrá ser concebida como un raciocinio sociológico. Passeron afirma que si una sociografía se comporta como una descripción social en que su validad solamente se confirme en un contexto único, no posee legitimidad sociológica a pesar de servir para la naturaleza literaria. Para que tenga legitimidad sociológica una sociografía necesita evocar una interacción con un concepto universal ${ }^{3}$.

Sin estar en contra la afirmación de Passeron nos preguntamos, con Mauger (1994), si es posible constituir un pensamiento a respecto de las interacciones recíprocas que entendemos como sociales, valiéndonos de una práctica como la de la escrita literaria. Mauger argumenta que autobiografías literarias, por ejemplo, pueden no apenas establecerse como objetos para un pensamiento sociológico pero, también, son herramientas útiles para las ciencias sociales. Mauger tiene un trabajo investigativo donde se vale de la teoría literaria y de la investigación bakhthiniana sobre Rabelais y sobre la cultura popular, para observar en las prácticas textuales de la representación de si elementos constitutivos de una condición de la propia expresividad, como también de aquello que de ese modo es descripto.

Por lo tanto, es necesario prestar atención y llevar en consideración el carácter de ilusión referencial que conlleva toda representación, incluso la científica. La literatura,

\footnotetext{
3 "On a souvent vu faire de la bonne littérature avec de la mauvaise sociologie, parfois même avec de la bonne, écrit-il, jamais de la bonne sociologie avec de la littérature, bonne ou mauvaise.” (PASSERON, 1989, p. 249)
}

\begin{tabular}{ll|l|l|l|l|l|l|} 
(C) ETD - Educ. temat. digit. & Campinas, SP & v.17 & n. 2 & p.271-287 & maio/ago. 2015 & ISSN 1676-2592
\end{tabular} 
especialmente la moderna, es entendida como un texto autoreferencial, o sea, un texto que habla de textos, un texto que se vale de la ilusión referencial para constituirse. En las ciencias sociales, a su vez, no hay un consenso a respecto del carácter inventivo de sus prácticas escriturales. De este modo nos preguntamos si las ciencias sociales, en la medida que operan con textualidades: ¿están libres de la ilusión referencial? Con eso, nos hacemos otra pregunta: ¿Se debe abandonar el ejercicio de la descripción social en la medida en que se concibe que, del punto de vista textual, no se pueda separar ficción y realidad? La cuestión es ponderada por la idea de que es difícil destacar categorías, en la construcción textual, que distingan - en definitiva - lo real de su representación. Como preconizan Nietzsche (1978) y también Paul Valéry $(1995 ; 1998)$ entre otros, no se alcanza lo real, apenas sus representaciones. En ese sentido, y paradójicamente, se admite que las expresividades son la propia realidad. O sea, lo real se configura como una invención que se prefigura por una tratativa textual, discursiva y fabuladora. Todo eso sin dejar de considerar que toda tratativa textual se da delante de una materialidad que le da razón y sentido.

Con esa relación expuesta, aquél que se otorga la tarea de observar y describir su entorno, no puede olvidarse de la tensión existente entre realidad y ficción y hacer de cuenta que aquello que crea al describir no es, también, una relación de ilusión referencial. Hay que preconizar que jamás se trata de una observación de lo real efectivamente, mismo cuando ajustada a la neutralidad y metodología de un observador con pretensiones científicas. Como dice Marshall Sahlins (2002, p. 7) ${ }^{4}$ parafraseando John Barth, la realidad es un precioso lugar para visitar — filosóficamente — pero nadie nunca vivió allá.

En ese sentido, todavía, se puede afirmar que la idea de sociedad y su constitución como asociaciones recíprocas (TARDE, 2207; LATOUR, 2012) son compuestas por una orden literaria, para no decir mítica. Las ideas de sociedades se reinventan por intermedio del relato que escogen para expresar sus identidades. Por ese camino pueden ser entendidas como hipertextualidades que se afirman en la constitución de imágenes que, a su vez, encuentran eco en un imaginario constituido por esos mismos relatos.

Hay que llevar en consideración que los relatos no solo constituyen identidades, como también estabilizan invisibilidades vía negatividad. Oscar Favre (1994) reflexiona a ese respecto cuando apunta para la invisibilidad indígena en el imaginario que compone la nación uruguaya. La idea de la inexistencia de una populación indígena autóctona en la región hace con que las circunstancias materiales, históricas y geográficas de las investigaciones se amparen por el recorte de esa invisibilidad que desarrolla toda su atención para características mayoritariamente de inmigración europea. Con esa actitud se repasa la idea de que la presencia indígena, mbyá guaraní, por ejemplo, se trata de inmigración reciente en el territorio nacional uruguayo. Po lo tanto, al admitir, por negatividade, que la presencia indígena no constituye las bases fundacionales de esa comunidad imaginada - en

4 "So to paraphrase John Barth, reality is a nice place to visit (philosophically), but no one ever lived there." 
contraposición a las recientes investigaciones que relatan esas presencias - se activa, por la ponderación de esas ausencias, paradójicamente, vía texto, sus presencias. O sea, este nuevo texto que admite que los anteriores operaban la invisibilidad retoma la propia invisibilidad como presencia y, con ese gesto de escritura, se constituye una visibilidad vía el relato que la admite ausente. Es decir, esas presencias ausentes se tornan realidad.

\section{SOBRE UNA DIDÁCTICA DE LA INVENCIÓN}

Con la finalidad de ampliar el campo de expresividades de las ciencias sociales y constituir el propio campo por la apropiación transversal de procedimientos de las artes, Howard Becker pasó a observar prácticas de descripción social de afuera del campo, pues no creía que la descripción social sería un privilegio de los científicos sociales y que el modo de las ciencias sociales fuera el único. Su interés está relacionado, por un lado à la experiencia que pudo tener con los trabajos de Dwight Conquergood en el Departamento de Estudios de la Performance en la Escuela de Comunicación y Artes de la Universidad de Northwestern, experiencia descrita en el libro Telling about Society y, por otro, a su propia experiencia como estudiante de ciencias sociales, profesor y, también, con su trato con la fotografía, el cine, el relato ficcional, la música y el teatro (BECKER, 2009).

Lo que Dwight Conquergood estudia y desarrolla entre los años de 1970 y 1990 es lo que se denominó de aspectos performativos de la sociedad. Conquergood llega a presentar sus resultados de investigación al respecto de refugiados asiáticos y pandillas de Chicago en la forma de performances. De esa interacción de Becker con Conquergood surge un curso que ambos denominan de Ciencias Sociales Performativas (Performing Social Science). Para Becker lo importante de esa investigación no es legitimar el campo de las ciencias sociales con otro modo de expresión de sus investigaciones - como era la preocupación de Passeron (1989) —, o sea, hacer de esa práctica materia para la validación del trabajo sociológico; lo más importante es una búsqueda de maneras que, más allá de las conocidas por los científicos sociales, se pueda comunicar un estudio de carácter sociológico. En nuestro entendimiento esa práctica, al buscar otros modos de expresión para el campo, amplia la propia concepción que se tiene del campo, o sea, interfiere en sus demarcaciones de fronteras y con eso cambia la noción sobre el carácter sociológico.

De ese modo Becker nos cuenta la experiencia en el seminario del curso describiendo que en el período en que fue ministrado cada semana era dedicada a una forma diferente de expresión, como el cine, el teatro, las tablas estadísticas etc; Becker indicaba lecturas y presentaba al grupo de estudiantes algo que provocase una reacción a las ideas estereotipadas sobre lo que constituía una forma apropiada de describir la sociedad (BECKER, 2009, p. 09).

De esa manera una sociografía actúa como un carácter constitutivo para observar, por las propias expresiones, un modo de ser en el hacer de aquellos que investigan y de los investigados sin, con todo, optar por una metodología demasiadamente dualista - que separa investigador de aquello que se investiga - , pues busca la instauración de una indisolubilidad 
entre conocimiento, poder y placer, entendiendo que mucho de la actividad pedagógica consiste en testar las formas por las cuales se produce significado y se representa, a nosotros mismos, las relaciones con los otros e con el ambiente en que se vive (GIROUX; SIMON, 1995, p. 107).

Se puede ponderar, con Lepetit (2001), que la interdisciplinaridad es una práctica ambigua, por ende se vale de incomprensiones parciales. En el ámbito literario se podría atribuir esa práctica al personaje borgeano Pierre Menard (BORGES, 1995b) que utiliza como técnica el anacronismo deliberado y las atribuciones erróneas; a la vez que esa técnica nos sirve como procedimiento en el mismo sentido afirmado por Chartier (2014), o sea, de que la transferencia de conceptos, problemas o métodos de un campo para otro no se realiza sin la transformación de estos campos. Se puede entender que tal movimiento ocurre como una transposición traductora y toda transposición comporta una traición, aunque sea parcial. Toda lectura opera, de algún modo, el error.

Por esa razón la sociografia que evocamos en este texto no se resume a un recorte social previamente construido, como defiende Passeron (1989) con relación a la sociología científica que, para él, difiere del ensayismo sociológico. Esta noción se vale de lo contrario, o sea, operar con la noción de ensayo adorniana (2003), entendiendo que forma de expresión y contenido no se separan. Con eso, la práctica didáctica busca traducir las fuerzas que se pueden observar en toda acción creadora, a través de formas que habiliten nuevas fuerzas, como el experimento de Dwight Conquergood al presentar sus investigaciones a través de performances.

En ese espacio didáctico de operación traductora la educación estrena e instituye un tránsito creador por intermedio de una lectura atenciosa e interactiva. Lectura que se establece y se considera como un flujo de asociaciones variadas donde ninguna es original o privilegiada. La lectura, en este caso, es concebida como una acción relacional que se enlaza por un efecto de redes heterogéneas siendo, todas ellas, lazos para una didáctica de la invención como desarrollada por Corazza (2013). A su vez, una didáctica de la invención actúa como una maniobra traductora que se forma como un tejido de citas, un gesto de combinaciones de elementos finitos con algún otro gesto anterior conformando que esa maniobra se establezca como una convergencia, o una, reciprocidad entre textos.

Esa convergencia puede ser entendida como una relación hipertextual, ya que se vale de un sentido de flujo interactivo para la lectura. En esa noción la actividad lectora se apropia de un montaje de relaciones transtextuales al modo de potencializar todo lo que se coloca en relación manifiesta o secreta con el otro, sean textos, imágenes, gestos, palabras, signos etc. Y la idea de hipertexto tiene de ser entendida como una red potencialmente infinita de conexiones (GENETTE, 1982; 1989).

Con eso podemos afirmar que una sociografía, valiéndose del sentido de hipertexto, tiene como propuesta establecer conexiones transversales que propicien el ejercicio de que se \begin{tabular}{l|l|l|l|l|l|l|} 
(C) ETD - Educ. temat. digit. & Campinas, SP & v.17 & n. 2 & p.271-287 & maio/ago. 2015 & ISSN 1676-2592
\end{tabular} 
haga una lectura que se activa como escritura. Intensificando la noción de que un espectador, consumidor y, también, un lector son productores que al leer, leen lo antiguo con lo nuevo. Con eso se busca explorar el territorio de una cultura de la convergencia, donde la recombinación es vista como una forma productiva, inventiva y no-excluyente de proliferar modos de leer culturas antes de caracterizar diferencias. En ese sentido lo que importa es leer la teoría como ficción y, con eso, hacer del pensamiento para la educación una fictio, es decir, dislocarla de una voluntad de verdad unívoca y esencialista al tenerla como una potencia de lo falso y que no pretende la obliteración de lo desconocido.

Para tanto la escritura importa como un modo de leer a sí mismo y de pertenecer, como partícipe, de la construcción de signos permitiendo los silencios sin habitarlos, insistentemente, con hegemonías colonizadoras. La voz y la letra de este que lee y se apropia es de todos y de ninguno, es suya y de la multitud que la comparte. Es un ejercicio de perderse en una red de signos y de perderse, también, como signo al formar pensamientos.

\section{LA LITERATURA DE GEORGES PEREC COMO DIDÁCTICA DE LA VIDA COTIDIANA}

La escrita de Georges Perec asume un aspecto autobiográfico que está en acuerdo con la idea de una sociografía como planteada hasta aquí. Georges Perec parece hacer una escritura de lo social buscando maneras de poner en escena acontecimientos de una experiencia vivida. Como si buscara mirar para la vida cotidiana por medio de una especie de descripción de asociaciones interactivas. Un conjunto de asociaciones de sí y de los objetos, espacio y tiempo en su entorno. Transformando los propios espacios en que se vive la cotidianidad, como las ciudades, en artefactos que personifican sus textos y, en reciprocidad, recrean el propio espacio textual como un espacio de asociaciones recíprocas. De este modo los espacios de lo social se prefiguran como textos o sea, los textos son alimentados por la propia descripción textual que les da razón de texto y, al mismo tiempo, de espacio de relaciones.

En este caso nos referimos a textos de la fase anterior a la entrada de Perec al Ouvroir de Littérature Potentielle (OuLiPo), o sea, fase que precede sus textos oulipianos. Hay que observar que OuLiPo puede ser traducido por Taller de Literatura Potencial (TaLiPo) y se trata de un grupo, más que un movimiento, fundado por François Le Lionnais e Raymond Queneau en el mes de noviembre del año 1960 en Francia. Muchos son los miembros del OuLiPo, entre los más conocidos están Georges Perec, el propio Raymond Queneau, Ítalo Calvino, Marcel Duchamp entre otros. El OuLiPo sigue existiendo y produciendo material de creación literaria. Recientemente, en 2014, el escritor argentino Eduardo Berti entró en la lista de los oulipianos reconocidos entre sí.

El objetivo del OuLiPo es el de crear y apropiarse de reglas, restricciones [contraintes], juegos, combinatorias para escribir. Tratando de encontrar nuevas formas 
poéticas y narrativas por intermedio de las relaciones de transferencia, traducciones, apropiaciones, reglamentos retóricos entre otros recursos destinados a la escritura.

Aunque la distinción de los textos de Perec, con relación a su fase oulipiana y la anterior, no se establezca sin hesitaciones se puede conferir algunas distintivas; Perec entró al OuLiPo en 1967. En la novela La vie mode d'emploi, por ejemplo, texto dedicado a Raymond Queneau y publicado en 1978, la restricción funciona como un modo de desvío colocando en escena varias vidas que se entrecruzan en simultaneidad. Se expone como un puzzle, un rompecabezas, pero también como un libro de aventuras, un juego, una lista que presenta ausencias. En este libro Perec presenta el cotidiano como inagotable, fecundo e impenetrable evocando la lectura como un erro, es decir, una lectura que funciona como un desvío incesante de recorrido, una deriva inmanente. Pero su primer libro Las cosas publicado en 1965, ya elabora esa temática de lo cotidiano en los nombres de las cosas, objetos recubiertos por el lenguaje publicitario; una escritura realista al extremo de las palabras y sus posibilidades relacionales.

Los textos perequianos, oulipianos y no-oulipianos, - o sea, que siguen una restricción para su construcción o no - conllevan cierta repetición temática como la autobiografía, el espacio, lo cotidiano, las ausencias, pero esos temas no insisten en una significación unívoca. Los textos de Perec buscan dar un efecto a respecto del tema que le sirve de impulso para la escritura. Para hablar de ausencias, por ejemplo, construye una novela lipogramática intitulada La disparition. Esa novela, publicada en 1969, cuenta el desaparecimiento de la letra e ausentando esa letra de todo el texto. Ese desaparecimiento hace con que cambie palabras, modifique la sintaxis, subvierta algunos códigos de escritura para que la misma siga siendo posible. Perec se vale de la idea de un libro lipogramático publicado en 1939 por Ernest Vincent Wright intitulado Gadsby. En ese sentido, lo que hace Perec es seguir una red de apropiaciones, como un ladrón que transforma lo que le interesa en repercusiones por intermedio de sus proyectos.

En 1967, mismo año en que entró al OuLiPo, publicó Un homme qui dort texto considerado autobiográfico y que coloca en tensión el espacio del cotidiano y de la solitud urbana. En ese texto su narrativa descriptiva se elabora como una estética de la creación autobiográfica donde narrar utilizando una tentativa exhaustiva de describir el mundo se torna, como en un mise en abîme, el propio problema que es narrado. Lo que se narra es la descripción como espacio de inscripción, dicho de otro modo, la descripción como constituidora de espacios. Lo que se narra es el propio acto descriptivo reteniendo la descripción como sistema de autodiferenciación.

Ese tema de la constitución del espacio textual es directamente desarrollado por Perec en el libro Espèces d'espaces, texto publicado en 1974. Una vez más podemos leer siendo provocados por un efecto que está más allá de su escrita, es decir, la utilización del espacio de las páginas que forman el libro tratan, justamente, de dar a ver la utilización e institución del 
espacio de esas hojas, o sea, la conformación del espacio se configura en lo que se dice y en la forma de incorporar el propio espacio de una página para decirlo.

Con eso podemos indicar que la literatura de Georges Perec proporciona un ejercicio para el ultrapasamiento de fronteras. Sus textos son imagéticos y performáticos y sus imágenes son textuales. Un ejemplo de imágenes retumbantemente textuales es la película $U n$ homme qui dort realizada en 1974 con dirección de Bernard Queysanne con el guion de Perec.

Si Perec se pone un problema para su literatura, podríamos decir que es el de encontrar modos de expresar al otro - mismo cuando ese otro es él mismo - aquello que fue visto, sentido, tocado, vivido, o sea, maneras de materializar encuentros. Se trata de proliferar diferencias a través de la repetición de aquello que conocemos y que nos alejamos por hábito de mecanismos de la propia repetición.

Al modo de Paul Valéry, tomado por los hechos de Leonardo Da Vinci, nos parece interesante dar atención a los esbozos, apuntes dispersos y otras cosas que son parte de nuestro cotidiano, como lo hizo Perec. Los tickets de compras, los sellos, las cartas y, hoy día, los twitters, selfies, blogs y todo lo que configura, o puede configurar, un gesto de acción viviente en la trama cotidiana. Como si pudiésemos, en la conjunción de esos restos y rastros de las cosas y acciones, tener una historia de lo que nos pasa sin un relato propiamente dicho. Algo como tener la efectuación de acontecimientos por el decir dado en la presencia de las cosas, como si estas presencias desconfiaran, siempre, de los nombres que les dan algún sentido unívoco.

Por lo tanto, materializar sus presencias en una escrita que las nombra se puede tornar un ejercicio que sea, más que darles un nombre o establecerles un sentido, un carácter de compartir con ellas la instauración de sus atmósferas. Esa tarea practicada en sala de aula, con elementos de la misma es como darle un límite expandido.

Esa tarea de evocar una sociografía para la educación sugiere provocar una relación anti-ilusionista, una vez que, con ese ejercicio, aquél que se toma la actividad de sociografiar el presente, disputa, constantemente, con un límite al darse cuenta que, a cada vez que se pone a escribir las relaciones, miradas o percibidas o, todavía, vividas, necesita inventarlas en la escrita y por la escrita. No existe ilusión posible que no sea construida por la coherencia espacio-temporal de una invención que es su creación.

El ejercicio de la escritura sirve como un modo de captar los hechos de lo cotidiano y colocar al practicante en una relación falsificadora de la realidad. De esa manera lo vivido se torna, de algún modo, literatura y esa práctica adviene como una didáctica de la traducción al mismo tiempo que coloca en presencia textual, el devenir de un atravesamiento de los hechos cotidianos de un aula. 


\section{NOTAS FINALES}

Lo que hemos destacado en este texto es una propuesta que perspective los encuentros al tornar presente algunos efectos producidos en una lectura de la atmósfera de un aula. $\mathrm{O}$ sea, encuentros con producciones que se exponen como procesos traductorios del aula y sus aparatos constituidores, como el currículo y la didáctica. Traducir como un proceso recíproco de relación con la alteridad. Tal vez de ese modo se pueda devenir con potencias poco exploradas en la práctica docente y en la educación en general. Tomar algunos procedimientos de escritura, como los de Georges Perec, como si fuera posible hacer un pacto con lo insignificante y lo efémero en la Educación. Lo insignificante seria lo no-significado y lo efémero la propia escena del aula y su espacio.

En el sentido presentado, el texto se permite dar un paso hacia un procedimiento de escritura que se autoriza autodenominarse sociografía. Eso ocurre en la medida en que la comprehende como una recombinación traductora de elementos relacionales entre cosas, personas, espacios y tiempos, o sea, relaciones entre un más allá antropocéntrico y antropomórfico.

Para que eso sea posible entiende lo social como una integración de todo lo que se pueda concebir como existente en relación. En el caso en que se insiere este texto, se escoge un aula como un dinamismo espacio-temporal donde se intenta producir presencias de esas conexiones ausentes por indefinición. Aspectos de lo infraordinario que habitan días de profesores y alumnos.

\section{REFERENCIAS}

ADORNO, Theodor Wiesengrund. Notas de literatura I. Tradução de Jorge Mattos Brito de Almeida. São Paulo: Ed. 34, 2003.

BORGES, Jorge Luis. EI hacedor. Madrid: Alianza, 1995a.

BORGES, Jorge Luis. Pierre Menard, autor del Quijote. In: BORGES, Jorge Luis. Ficciones. Barcelona: Emecé, 1995b, p.43-54.

BORGES, Jorge Luis. Pierre Menard, autor do Quixote. In: BORGES, Jorge Luis. Ficções. Tradução de Davi Arrigucci Junior. São Paulo: Companhia das Letras, 2012, p. 34-45.

BORGES, Jorge Luis. Valéry como símbolo. In: BORGES, Jorge Luis. Outras inquisições. Tradução de Davi Arriguchi Junior. São Paulo: Companhia das Letras, 2007, p. 91-93.

CHARTIER, Roger. O mundo como representação. Estudos Avançados. São Paulo, v. 5, n. 11, p. 173-191, jan./abr. 1991. Disponível em: 〈http://goo.gl/WRAAFL〉. Acesso em: 06 jun. 2014. ISSN 18069592.

CORAZZA, Sandra Mara. O que se transcria em educação? Porto Alegre: UFRGS: Doisa, 2013.

\begin{tabular}{l|l|l|l|l|l|l|} 
(C) ETD-Educ. temat. digit. & Campinas, SP & v.17 & n. 2 & p.271-287 & maio/ago. 2015 & ISSN 1676-2592
\end{tabular} 
CORAZZA, Sandra Mara. Os cantos de Fouror: escrileitura em filosofia-educação. Porto Alegre: Sulina: UFRGS, 2008.

DELEUZE, Gilles. Whitman. In: DELEUZE, Gilles. Crítica e clínica. Tradução de Peter Pál Pelbart. São Paulo: Ed. 34, 1997, p.67-72.

DELEUZE, Gilles. Spinoza y el problema de la expresión. Tradução de Horst Vogel. Barcelona: Atajos, 1996.

DEWEY, John. Vida e educação. Tradução de Anísio Teixeira. São Paulo: Melhoramentos, 1965.

FAVRE, Oscar Padrón. Sangre indígena en el Uruguay. Durazno: Libros del autor, 1994.

FLUSSER, Vilém. Da ficção. O Diário de Ribeirão Preto. Ribeirão Preto, 26 ago. 1966.

Disponível em: 〈http://paginas.terra.com.br/arte/dubitoergosum/arquivo02.htm>. Acesso em: 16 mai. 2006.

GENETTE, Gérard. Palimpsestes: la littérature au second degré. Paris: Ed. du Seuil, 1982.

GENETTE, Gérard. Palimpsestos: la literatura en segundo grado. Madrid: Taurus, 1989.

GIROUX, Henry; SIMON, Roger. Cultura popular e pedagogia crítica: a vida cotidiana como base para o conhecimento curricular. In. SILVA, Tomaz Tadeu (Org.); MOREIRA, Antonio Flávio (Org.) Currículo, cultura e sociedade. São Paulo: Cortez, 1995, p. 93-124.

GORSKI, Sonnia Romero (Org.) Antropología social y cultural en Uruguay. Montevideo: UDELAR, 2000.

KUHN, Thomas. A estrutura das revoluções científicas. Tradução de Beatriz Vianna Boeira e Nelson Boeira. São Paulo: Perspectiva, 1998.

LATOUR, Bruno. Reagregando o social: uma introdução à teoria do ator-rede. Tradução de Gilson César Cardoso de Sousa. Salvador: Bauru; EDUFBA:EDUSC, 2012.

LEPETIT, Bernard. Por uma nova história urbana. Tradução de Cely Arena. São Paulo: Ed. EDUSP, 2001.

MATOS, Sônia Regina da Luz. Procedimentos de escritura e afectologia na alfabetização de crianças: abordagens cruzadas entre a filosofia da diferença e a psicologia intercultural. 2014. 205 f. Tese (Doutorado em Educação) - Faculdade de Educação, Universidade Federal do Rio Grande do Sul, Porto Alegre, RS, 2014.

MAUGER, Gérard. Les autobiographies littéraires: objets et outils de recherche sur les milieux populaires. Politix : Revue des Sciences Sociales Du Politique. Paris, v. 7, n. 27, p. 32-44, jul./ago. 1994. Disponível em : 〈http://goo.gl/1Je9wH> Acesso em : 24 jul. 2015. ISSN : $0295-2319$.

NANCY, Jean-Luc. Ser singular plural. Tradução de Antonio Tudela Sancho. Madrid: Arena, 2006. 
NIETZSCHE, Friedrich. Sobre verdade e mentira no sentido extra-moral. Tradução de Rubens Rodrigues Torres Filho. In: Obras incompletas. São Paulo: Abril Cultural, 1978, p. 43-52.

NORDHOLT, Annleies Schulte. Georges Perec: topographies parisiennes du flâneur. Revue Életronique de Littérature Française. Leiden, v. 2, n. 1, p. 66-86, 2008. Disponível em: <http://goo.gl/fc0hcs> Acesso em: 24 jul. 2015. ISSN : 1873 - 5045.

PASSERON, Jean-Claude. L'illusión du monde réel : -graphie, -logie, -nomie. In. GRIGNON, Claude ; PASSERON, Jean-Claude. Le savant et le populaire : misérabilisme et populisme en sociologie et en littérature. Paris : Hautes Études : Gallimard : Seuil, 1989.

PEREC, Georges. Espèces d'espaces : Jounal d'um usager de l'espace. Paris: Galilèe, 1974.

PEREC, Georges. Tentative d'épuisement d'un lieu parisien. Paris: Christian Bourgois, 2008.

PEREC, Georges. Lo infraordinario. Tradução de Mercedes Cebrián. Madrid: Impedimenta, 2010.

REZENDE, Luiz. É escrevendo que se vira escrevedor. In. QUENEAU, Raymond.

Exercícios de estilo. Tradução de Luiz Rezende. Rio de Janeiro: Imago, 1995, p. 11-15.

SAHLINS, Marshall. Waiting for Foucault, Still. Chicago: Prickly Paradigm Press, 2002.

SILVA, Tomaz Tadeu da. Documentos de identidade: uma introdução às teorias do currículo. Belo Horizonte: Autêntica, 2011.

TARDE, Gabriel. Monadologia e sociologia e outros ensaios. Tradução de Paulo Neves. São Paulo: Cosac Naify, 2007.

VALÉRY, Paul. Introdução ao método de Leonardo da Vinci. Tradução de Geraldo Gérson de Souza. São Paulo: Ed. 34, 1998.

VALÉRY, Paul. Monsieur Teste. Tradução de Cristina Murachco. São Paulo: Ática, 1997.

VALÉRY, Paul. Poesia e pensamento abstrato. Tradução de João Alexandre Barbosa. In. VALÉRY, Paul. Variedades. São Paulo: Iluminuras, 1991, p. 201-218.

VALÉRY, Paul. Variations sur les bucoliques. Paris: Gallimard, 1956.

VILA-MATAS, Enrique. El mal de Montano. Barcelona: Anagrama, 2002.

WITTGENSTEIN, Ludwig. Investigações filosóficas. Tradução de José Carlos Bruni. Rio de Janeiro: Nova Cultural, 1991. 
LAMELA ADÓ, Máximo Daniel; CORAZZA, Sandra Mara. A escrita sociográfica como didática transcriadora e produtora de presença. ETD - Educação Temática Digital, Campinas, SP, v. 17, n. 2, p. 271-288, ago. 2015. ISSN 1676-2592. Disponível em:

<http://periodicos.sbu.unicamp.br/ojs/index.php/etd/article/view/8635647>. Acesso em: 27 ago. 2015. 